Revista Iberoamericana, Vol. LXXII, Núms. 215-216, Abril-Septiembre 2006, 587-605

\title{
LA ECONOMÍA POÉTICA DEL MAR: PATRIMONIO Y DESBORDAMIENTO EN MAREMOTO DE NERUDA*
}

\author{
POR \\ Luis E. CÁRCAmo-Huechante \\ Universidad de Harvard
}

No hay figura simbólicamente más dominante en la poesía de Pablo Neruda que aquella del mar. El mar irrumpe en sus libros una y otra vez. A veces los inunda y los envuelve por completo. Otras, aparece a la manera de intempestivo oleaje, vía un poema o uno u otro verso. Junto a los escenarios del bosque y de la tierra, la presencia simbólica del agua, sea en la forma de lluvia, río o directamente como mar, se hace parte de aquella confluencia siempre ambivalente entre letra y naturaleza que atraviesa el imaginario poético de Neruda. ${ }^{1}$ Si bien es cierto que el sujeto de su escritura pareciera estar constantemente navegando en busca de tierra firme, para así establecer y erigir su voz, el mar se inscribe en sus páginas desatando un particular dinamismo y un movimiento que en cierta forma atenúa los efectos de su poética de raigambre telúrica y monumentalizadora. Así ocurre, por ejemplo, en Residencia en la tierra y en Canto general, obras que consagrarán la presencia de Neruda en el contexto poético internacional del siglo veinte. Por un lado, en su registro residenciario de los treinta, la imágenes marinas metaforizan un estado temporal y existencial de infinito desasosiego: el poeta se enfrenta a su propio “abismo oceánico y nocturno" (Alonso, 289). Por otro lado, en la sección "El gran océano" del Canto general, se altera radicalmente el trayecto histórico y social del libro. En dicha variación, el yo poético termina sumergiéndose, y prácticamente desaparece, en las aguas de un mundo marino de vastas connotaciones; de este modo, la salvaje y "espaciosa autonomía” del mar parece imponerse, aunque, luego, al cierre de esta sección e inicios de la siguiente, se restituye la arraigada voz épica del yo nerudiano. ${ }^{2}$ Diversos segmentos de la obra de Neruda están marcados por la tensión que se establece cuando el mar desata estados de convulsión. Los cataclismos marítimos constituyen, en este sentido, un

\footnotetext{
* Una versión preliminar de este ensayo se presentó en el seminario "Modernism and Its Contexts" en el Humanities Center de Harvard en febrero del 2003, ocasión en la cual tuve la oportunidad de recibir las sugerencias de colegas y estudiantes graduados. Los diálogos con Joaquim Coelho, Juan Armando Epple, Yunte Huang y Mary Gaylord, así como la asistencia de Rafael Dávila, Cecilia Enjuto y Juan Pablo Rivera han sido de vital importancia para la presente incursión en aguas nerudianas.

${ }^{1}$ Para un análisis concentrado de estas dimensiones "naturales" del registro nerudiano, véase Yurkievich, Fundadores 231-315.

${ }^{2}$ Véase Neruda, Canto general 547-591.
} 
particular desafío para el astrolabio del poeta: ¿cómo contener en la escritura aquello que implica descontrol y desvarío? ¿Qué tipo de tensión aflora en la geografía formal y semántica de un libro cuando la figura invocada -el mar-se manifiesta como cataclismo y/o catástrofe?

Con respecto a estas interrogantes, Maremoto, conjunto poético escrito por Pablo Neruda entre 1969 y 1970, resulta bastante revelador. El título mismo ya define el motivo principal del libro: maremoto, de mare, mar, y de motus, movimiento. El término en efecto designa aquél fenómeno de agitación violenta de las aguas del mar a causa del desplazamiento de determinadas placas geológicas del subsuelo, y que, generalmente, resulta en devastadoras inundaciones de la superficie terrestre. Así los textos poéticos de Neruda se dedican a loar al maremoto y a sus efectos, a partir de la figura de un mar y un poeta que se hacen omnipresentes y se aproximan, aunque acto seguido optan por distanciarse uno del otro. Poeta y mar tempestuoso entran en contacto, para luego, poéticamente transfigurados, devolverse a sus respectivos espacios. En este juego de roce y distanciamiento parecen asimismo revelarse aspectos que, en clave simbólica, vinculan el espacio oceánico y el universo sensual, lírico, político y social del poeta.

Maremoto se compone de diecisiete poemas, técnicamente con predominio métrico del eneasílabo y de una asonancia irregular que resalta el tono lúdico que recorre sus páginas. El primero de ellos, titulado “Maremoto”, y el último, “Adiós a los productos del mar”, son los poemas más extensos del libro: cincuenta y seis y cuarenta y seis versos, respectivamente. Los quince poemas restantes son breves y constituyen un elogio verbal y visual a los elementos dejados por el mar. ${ }^{3}$ En efecto, los poemas de Neruda, acompañados por las quince xilografías de Carin Oldfelt Hjertonsson, artista sueca, hacen visible una creativa cohabitación de lo plástico y lo verbal. Así, el puerco espín, el pez espada, el delfín de bronce, el pulpo, la anémona, la estrella de mar o el salmón, junto a las algas, los erizos, las conchas y los picorocos, forman un universo tanto referencial como visual en estas páginas.

Maremoto fue publicado por primera vez en 1970, en una edición numerada de 110 ejemplares. Este hecho, tratándose de un poeta de difusión masiva como lo fue siempre Neruda, sugiere la opción del poeta, tanto estética como económica, por el libro de colección. En 1991, Pehuén Editores procedió a reimprimirlo, poniendo en circulación una edición de lujo de quinientos ejemplares, y otra de alcance masivo de cuatro mil copias; preservando los aspectos gráficos y visuales de la publicación original: tanto los grabados de Carin Oldfelt como la ausencia de numeración de página. Llama la atención que este volumen ni tras su primera ni tras su segunda edición concitara mayor atención en los circuitos de la crítica especializada; de hecho, hasta donde he logrado investigar, no existe, hasta ahora, ningún estudio disponible sobre este libro en específico, dato curioso en el contexto de la siempre vasta producción crítica en torno a la poesía de Neruda.

Lo que me propongo en este ensayo es abordar tal corpus poético como registro de una contradictoria oscilación entre cierto orden "patrimonialista” del poeta-colector y un

\footnotetext{
${ }^{3}$ Dentro de estos quince poemas restantes, hay dos de siete versos, cinco de ocho versos, tres de nueve versos, dos de diez versos, uno de doce versos, uno de trece versos y uno de quince versos.
} 
universo natural que, encarnado en la figura del mar, se vuelve indómito e irredimible. De este modo, los poemas oscilan entre una suerte de economía -la de la acumulación y el almacenamiento-y determinado impulso simbólico-aquél del movimiento y el desborde. En otras palabras, se observa, por un lado, que el afán de asignarle al mar una condición de reserva natural constituiría un registro análogo al de la perspectiva proteccionista propiciada desde el Estado, en el escenario chileno de fines del 60. Por otro lado, en gesto claramente distintivo, el discurso poético de Neruda termina otorgándole al mar un carácter de bien simbólico, situándolo en una dimensión sublime que excedería la racionalidad productiva y reguladora de la referida óptica estatal.

Sin embargo, y a contrapelo de esto último, una especie de estatismo de la imagen presente en estos poemas establece una relación paradójica con su propia temática, el de una naturaleza -el maremoto y el mar- que, en su indómito movimiento, resistiría la codificación y transacción de los sistemas. El océano y el poeta se hallan así sometidos a un conflicto y a un juego de turbulencias expresivas, aproximándose y separándose dentro de la tensión general del libro.

Los diecisiete poemas de Maremoto, aún en el vértigo del cataclismo, optan por rendir tributo lírico al mar y a ensalzar los efectos de su violento desbordamiento. Si en la tradición lírica -y aún en la modernidad poética- el sujeto atribuía connotaciones negativas a la imagen del mar tempestuoso y buscaba, en determinados casos, ejercer control sobre su turbulencia neptuniana, Neruda parece privilegiar su celebración. ${ }^{4}$ En este aspecto, el poeta chileno registra una relación con el espacio marino que también establece diferencias al interior de su propia trayectoria poética, en la medida que aquí se distancia claramente de la visión abismal del espacio oceánico presente en Residencia en la tierra y adopta un tono juguetón más próximo a aquél inaugurado con sus Odas elementales (1954). En este sentido, uno se podría preguntar, ¿qué es lo que lleva a Neruda a escribir estas páginas como una especie de elogio a la hecatombe marina? ¿Cuáles, finalmente, son las capas quizás no tanto geológicas como ideológicas que Neruda está buscando remover en el panorama discursivo de la época en que escribe y publica, es decir, fines de los sesenta

\footnotetext{
${ }^{4}$ En el marco de la lírica castellana, Begoña López Bueno sostiene que el topos fluvial fue preferido como "el lugar ameno" de la poesía de raigambre petrarquista (en específico, Garcilaso de la Vega, Cetina, Acuña y Herrera). López Bueno suscribe, aunque con sus matices, la tesis -planteada por Gonzalo Sobejano- acerca de que el mar adquiriría plena valoración estética con los poetas románticos, es decir, mucho después de la poesía medieval, clásica y renacentista (López Bueno, 12 44). Con respecto a la poesía moderna europea, Bachelard, sin embargo, subraya una cierta preferencia por el topos de las aguas calmas aún en los precursores de la modernidad romántica -por ejemplo, Wordsworth asociaría los ríos y los arroyos con "la música de la humanidad”; a su vez, una expresa voluntad de control sobre las fuerzas neptunianas se trasluciría en importantes pasajes del Fausto de Goethe. Al comentar este último, el teórico francés apunta: "Commander a la mer est un rêve surhumain. C'est à la fois una volonte de gene et une volonté d'enfant” (Bachelard, 240). Sin desconocer estas tradiciones, Neruda asumiría una sensibilidad más cercana a la simpatía rimbaudiana por el pathos del mar tempestuoso. Como antecedente del elogio nerudiano al maremoto, piénsese, por ejemplo, en los siguientes versos de "Le bateau ivre” de J.A. Rimbaud: “La tempête a béni mes éveils maritimes. /Plus léger qu’un bouchon j’ai dansé sur les flots/ Qu’on appelle rouleurs éternels de victimes, / Dix nuits, sans regretter l’oeil niais des falots !” (Rimbaud, 9).
} 
y principios de los setenta? Es evidente, en todo caso, que, aún en su violencia caótica, el poeta encuentra elementos positivos en la catástrofe.

PATRIMONIO Y DESORDEN

En el registro lírico de las páginas del libro, el mar deviene en patrimonio y don que, en su natural y generosa abundancia, excedería el interés económico inmediato. El poema que abre el libro Maremoto, bajo título epónimo, hace esto evidente ya en sus primeros versos:

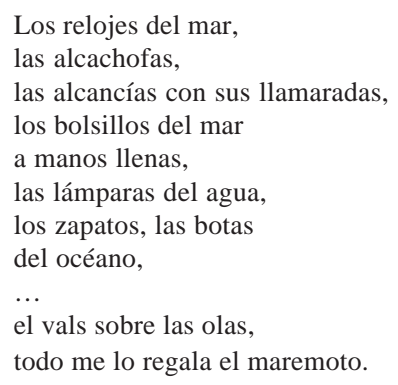

El recurso de la enumeración usado en estos versos resalta una subyacente lógica de acumulación y almacenamiento. En su análisis de la producción poética nerudiana de la primera mitad del siglo veinte, Amado Alonso había advertido el fenómeno de "las anomalías de las enumeraciones" como un recurso característico de esta etapa del poeta (136-141). ${ }^{5}$ No obstante, lo que se observa en este fragmento de Maremoto es más bien un orden, en la medida que se establece una acumulación de referentes a través de los sustantivos, sin que se produzcan mayor trastorno en el nivel sintáctico o en el gramatical. Al mismo tiempo, en el todo del libro, la convulsión oceánica pone a la vista un sinnúmero de objetos y seres que, aunque siendo caracterizados como "variados e inútiles tesoros", se van catalogando minuciosa y acumulativamente al interior de esta especie de librogalería (poemas, dibujos).

La retórica de la acumulación y la enumeración parecen así fundirse en Maremoto. ${ }^{6}$ En efecto, aquello que el crítico Julio Ortega denominara “el discurso de la abundancia” es lo que cobra forma específica en la lógica acumulativa y enumerativa que se patentiza en estos primeros versos del conjunto nerudiano: "las alcancías con sus llamaradas, / los

\footnotetext{
${ }^{5}$ En el contexto crítico de los cuarenta, las elaboraciones de Alonso, en torno a lo que denomina "el hacinamiento de membra disjecta y de objetos heterogéneos en los versos de Neruda” (312) serán un punto de referencia clave para la caracterización de "la enumeración caótica" en la poesía moderna que va a desarrollar Leo Spitzer (24). Sin duda que tanto Alonso como Spitzer tienen principalmente a la vista la etapa nerudiana de Residencia en la tierra.

${ }^{6}$ En general, los límites de la acumulación y la enumeración no resultan siempre claros. Al respecto, véase Marchese y Forradelas, 17-18.
} 
bolsillos del mar / a manos llenas". ${ }^{7}$ Figuras de almacenamiento (las alcancías y los bolsillos), junto a imágenes de abundancia, sugieren aquí una riqueza acumulada.

En dicha abundancia material, varias imágenes del fragmento citado nos sugieren un océano vestido y figurado de un modo humano y moderno -los relojes, los bolsillos, los zapatos, las botas. Pareciera que el mar, en algún sentido, no constituiría una figura extraña e intimidante sino más bien que, en su dimensión económico-simbólica, haría alusión a un Neptuno humano y solidario. El maremoto resulta ser, de parte de la naturaleza, un ritual de ostentación, un despliegue exhibicionista de sus dotes y sus dones, que luego adquiere una dimensión festiva -“el vals sobre las olas”- y proveedora -“todo me lo regala el maremoto”.

De este modo, el poeta no hace sino celebrar el desbordamiento oceánico, como lo testifican los versos con que se cierra este primer poema: "Yo sólo soy testigo / de la electricidad y la hermosura / que llenan el sosiego devorante.” No se trata, vemos, de un elogio al mar como locus de la quietud -las aguas calmas- sino a su estado de convulsión. Así, se trata nada menos que de la celebración de una catástrofe, con antecedentes concretos en la época: el maremoto de 1960 en el sur de Chile. ${ }^{8}$ El maremoto provocado por éste tuvo un enorme costo humano, redefiniendo vastas zonas del paisaje rural y urbano de la región. De allí que no deje de resultar sorprendente el tono lúdico y festivo de este corpus, más aún si se considera que el propio Neruda, mientras se hallaba en París, recibió con conmoción la noticia del fenómeno telúrico y acuático que asediaba sus tierras de infancia (Teitelboim, 402-3). ${ }^{9}$

No se trata, no obstante, de un tono celebratorio sin fisuras. En efecto, hacia el final del poema inaugural del libro, el sujeto nerudiano expresa un cierto desasosiego ante el cataclismo oceánico:

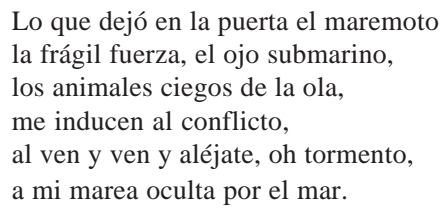

\footnotetext{
${ }^{7}$ Para Ortega, "el discurso de la abundancia” consistiría en la ubicuidad de "una versión fecunda de las formas y del sentido" (11) en el devenir de la literatura latinoamericana. Resulta curioso que no considere la poesía de Neruda en su estudio, toda vez que ésta, en mi opinión, ilustra claramente esta categoría propuesta para interpretar la imaginación literaria hispanoamericana.

${ }^{8}$ A consecuencia de un drástico remezón y desplazamiento en la placa geológica del subsuelo sudamericano, un terremoto de vastas proporciones se desencadenaría el 22 de mayo 1960, entre la provincia de Concepción y la península de Taitao en el sur de Chile, provocando lo que se denominaría "el Tsunami chileno". El maremoto mismo se concentraría en las provincias de Valdivia y Puerto Montt, dejando un saldo de aproximadamente diez mil personas muertas, además de cuantiosos daños en zonas urbanas, rurales y costeras de la región.

${ }^{9}$ Esta conmoción del poeta cobrará forma en el poema "Terremoto en Chile”, incluido en su libro La barcarola (1964-1967). Véase Neruda La barcarola, 42-45.
} 
Estos versos, como vemos, develan el lado más trágico de la experiencia del maremoto, dejando aflorar las aristas del “conflicto” y el "tormento”, tono grave que se patentiza, en el nivel prosódico, a partir de la ubicua presencia de sonidos rematados en la vocal "o”, y en el giro apostrófico: “oh”. El maremoto se torna tormento (estado subjetivo) y no tormenta (correlato objetivo). El tono del "ven y ven y aléjate, oh tormento” nos transmite así aquél estado de perturbación que experimentara el propio poeta tras el maremoto que azotara las costas del sur chileno en 1960.

En este primer poema del libro, el tono y la actitud del sujeto oscilan entre el regocijo y el juego, la inquietud y el conflicto. En el acontecimiento de la catástrofe, se revela, al mismo tiempo, lo positivo y lo negativo, lo luminoso y lo oscuro; oscilar contradictorio que se patentiza en este poema de apertura: "Ser y no ser aquí se amalgaron / en radiantes y hambrientas estructuras: / arde la vida y sale / a pasear un relámpago la muerte”. Dentro de este tramado contradictorio del "ser y no ser", de lo viviente y lo inánime, emerge también una oscilación entre presencia y ausencia. Si el maremoto es un movimiento que exalta el flujo oceánico y lo vuelve hirperbólicamente presente, el mar en sí se transforma en una figura enigmática e inasible. Esta ausencia aparece subrayada en el poema "Conchas":

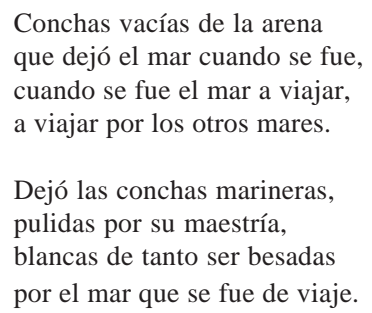

Los objetos arrojados por el cataclismo oceánico quedan allí para exhibir el trabajo artesano de la naturaleza, en este caso, el mar: “Dejó las conchas marinas / pulidas por su maestría”. He aquí entonces el mar como figura-¿la fábula del propio sujeto poético?-que se hace presente y se va, que se exhibe y luego se esfuma. Esta dimensión escurridiza y enigmática del mar se hace aún más evidente en los versos que cierran el antepenúltimo poema del libro, "Albacoras”:

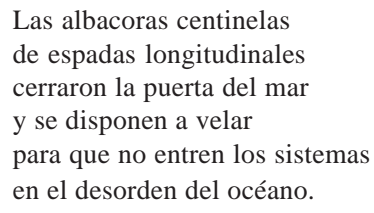

El mar comporta así una figura informe e indomable frente a "los sistemas”. Mar y maremoto rebasan la comprensión racional, deviniendo inconmensurables: "el desorden del océano”. Esta invocación de una naturaleza desbordante y trascendente que se torna 
“supernatural”, evoca asimismo el impulso hacia "la idealidad vacía”, “la vaga otredad” que advierte Hugo Friedrich en el inicio de la poesía moderna, particularmente en Baudelaire, Rimbaud y Mallarmé (31). Esta utopía nerudiana de la naturaleza concentrada en la figura del mar, se puede entender como una forma poética de abordar la tensión simbólica entre la episteme de la racionalidad industrialista y productivista de la modernidad y la otra lógica de la experiencia lírica y artística, revinculada imaginaria y arcaicamente al locus de la naturaleza.

Es evidente que, en este sentido, Maremoto sugiere un corte con las narrativas del industrialismo vigente en su época y abre la posibilidad de una otredad que se distancia de "los sistemas". El corpus poético nerudiano apela a un flujo imaginario que, hasta cierto punto, escapa a la circulación económica y a la lógica de la planificación propiciada por el Estado Benefactor y la "vía chilena al socialismo". Sin duda que con éstas últimas, y como ya lo he sugerido con anterioridad, hay determinadas homologías de sentido, específicamente en el trato del mar como reserva natural; pero, al mismo tiempo, el registro lírico de Neruda se desvía hacia otras rutas, por otra "vía”, más allá de lo nacional -“la vía chilena”-y más allá del paradigma occidental de la izquierda moderna -el "socialismo"insinuando, a través de la simbólica del mar, la radicalidad inconmesurable de toda utopía.

En la agitada coyuntura política de los años 69 y 70 en Chile, y en la cual Neruda participaba activamente, se vivía una atmósfera de intenso cálculo político en función de fraguar o bloquear el triunfo electoral de Salvador Allende y la Unidad Popular. Es sugerente que, en este contexto, el poeta chileno escriba un conjunto poético como Maremoto que comporta un cierto impulso utópico de inconmensurabilidad: vía este corpus el poeta subraya la amplitud de su compromiso, poniendo así de relieve su propio desborde, al resaltar su vínculo poético con el dominio primordial de la naturaleza. Esta convicción a la vez poética y política se establece a través de la simbólica exuberante del maremoto y que atraviesa -como enviones de sucesivos oleajes-el cauce de estas páginas.

Desde el punto de vista de la experiencia estética, este imaginario convulso y tempestuoso comporta determinados rasgos de sublimidad, en un sentido kantiano. Cabe recordar que para el filósofo "la naturaleza suscita las más veces las ideas de lo sublime cuando es contemplada en su caos y en el desorden e ímpetu destructor más salvajes e irregulares con tal de que se pueda ver grandiosidad y potencia,” todo lo cual adquiriría sentido al irrumpir esta fuerza en un plano subjetivo, capaz, a su vez, de imprimir “sublimidad en la representación de la naturaleza” (Kant, 91).

En el registro nerudiano, mar y maremoto afloran en sus dimensiones desbordantes, como se observa por ejemplo en los versos finales del primer poema del libro: "Yo sólo soy testigo / de la electricidad y la hermosura / que llenan el sosiego devorante". Pero al mismo tiempo, en la misma apertura, el discurso poético de Neruda instala la figura de un yo que, en su estremecimiento, se vuelve contemplativo, como lo propone Kant. Luego, en los textos siguientes, el yo opta por la ausencia, y, en algunos otros, por su desdoblamiento en torno a los entes oceánicos para, finalmente, en el último poema, volver a restituir su presencia.

El libro de Neruda dramatiza, de este modo, la tensión constante entre el impulso indómito asignado por el sujeto a la naturaleza y la codificación de lenguaje que, paradójicamente, hacen posible su poder enunciativo. En el marco de un orden verbal y 
plástico de la expresión se elogia aquella sensación de grandiosidad experimentada ante los movimientos y cataclismos del mar, así como aquella "belleza natural” resultante de dicho flujo océanico y que cobra forma visible en "los productos del mar." Son estos últimos los que le permiten al poeta reponerse del "sosiego devorante" del cataclismo marino y establecer una relación lúdica y placentera con el mismo: de hecho, los quince poemas dedicados a los frutos del mar, de forma simple y compacta, oscilan entre el tono juguetón y la actitud reposada. ${ }^{10}$

En contraste, en los poemas "Maremoto" y "Adiós a los productos del mar," los versos discurren a la manera de un torrente. Para usar los términos con que Jean Franco se ha referido a la retórica de algunos tramos del Canto general, en estos dos poemas "las palabras fluyen” y, en dicho devenir, parecen emular un discurso hablado que muestra cierta proximidad simbólica con el movimiento acuático (Franco 275). El discurso poético en ambos poemas adopta una fluidez expresiva mediante la disposición irregular de sus versos sobre la página. No obstante, el tono grave de "Maremoto" es relevado por el impulso lúdico que marca la dicción de “Adiós a los productos del mar”. Este último, en un tono decididamente juguetón, exalta la posición activa del poeta en el seno de la vida pública nacional y se explaya en el deseo de que los productos del mar retornen a través de las "hojas” del libro (cultura letrada) a su hábitat terrestre y marino (naturaleza): “a la razón / secreta de la roca”.

¿ESTATISMO DEL COLECTOR?

Los cruces entre plástica y poesía no son nuevos en la poesía de Neruda y, como lo han sugerido varios estudios, se pueden rastrear con nitidez desde el período del Canto general por el significativo diálogo que mantiene con las propuestas estéticas del muralismo mexicano. ${ }^{11}$ En este sentido la interacción entre dibujo y poema en Maremoto no es accidental, en cuanto forma además parte de la génesis misma del libro. Según se apunta en la "Nota del editor” de 1991, las xilografías de la artista sueca Carin Oldfelt Hjertonsson fueron claves para Neruda en la concepción de este conjunto poético: "lo habían motivado para escribir un conjunto de poemas vinculados al mundo marino” (s/ p). ${ }^{12}$

Es más que evidente entonces la existencia de un principio ecfrástico en la construcción misma de este corpus. Los dibujos no constituyen meras ilustraciones de los poemas; existe, de hecho, una continuidad entre el tipo de representación operado por las xilografías y el de los textos nerudianos. A nivel formal, ambos acuden a un lenguaje figurativo e icónico que, hasta cierto punto, aisla y congela la imagen de los seres

${ }^{10}$ Como se ha indicado previamente, estos poemas se componen mayormente de eneasílabos, hecho que les otorga cierta forma compacta.

${ }^{11}$ En su libro Neruda’s Ekphrastic Experience, Hugo Méndez-Ramírez analiza la relación de Neruda con la estética del muralismo mexicano.

${ }^{12}$ El estudioso Hernán Loyola plantea la hipótesis de que existiría una relación de continuidad entre los textos de Maremoto y los de Fin de mundo (1969). A su juicio, "Neruda los habría desgajado de ese libro cuando entrevió la posibilidad de un volumen híbrido, de esos que mucho le gustaban, en colaboración con la artista sueca Carin Oldfelt Hjertonsson” (Loyola 2004, 167). 
retratados. Las xilografías de Carin Oldfelt, en base al uso evidente de dos placas, se caracterizan por la incorporación de dos colores, sobre fondo blanco. Cada impreso produce así una imagen estática. La mediación de la técnica xilográfica también se transfiere a la retórica misma de los poemas-retratos del corpus nerudiano, en la medida que estos imprimen un cierto estatismo a sus objetos de representación.

De los dieciséis poemas del libro, catorce constituyen desarrollos de los títulos, centrados en el referente poetizado: "Picoroco”, “Erizo”, “Conchas”, entre otros. Siguiendo la imagen del dibujo impreso en la página conlindante, cada poema opera como imagen del ente en cuestión, compartiendo con las xilografías el apego nominalista a los entes poetizados, al mismo tiempo que dichos seres -referentes de cada poema-no son otra cosa que efectos mediáticos de la imagen xilográfica. ${ }^{13}$ El primer poema de esta serie, "Picoroco", marca la pauta:

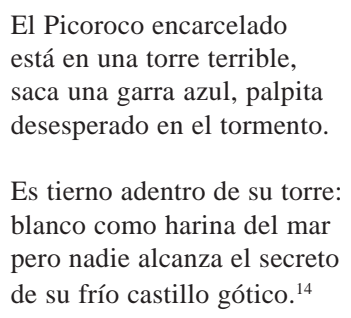

Estos ocho versos del poema, divididos simétricamente en dos estrofas y compuestos mayormente por eneasílabos, presentan un orden compacto y orgánico. A partir del uso de los verbos ser y estar, en los versos iniciales de ambas estrofas, se establece una cierta estaticidad de la imagen. El verbo estar, que abre el segundo verso, fija la representación desde el comienzo. De modo similar, acontece con el es que abre la segunda estrofa, expresión verbal que implica una definición de identidad. Sin embargo, el tercer y cuarto verso introducen notables variaciones: "saca una garra azul, palpita /desesperado en el tormento”. Los usos verbales y nominales, y en particular la adjetivación aquí presente, complican la lógica icónica de la imagen, para introducir cierto dinamismo, una suerte de retorcido movimiento al interior de la misma. Aparte de los adjetivos y sustantivos que, a un nivel semántico, sugieren desesperación y sufrimiento, el tramado aliterativo de las erres tiende a provocar a su vez ásperos relieves de sonido y sentido. ${ }^{15}$

\footnotetext{
${ }^{13}$ Respecto del nominalismo en la poesía de Neruda, Javier Ciordia ha apuntado que éste "quiso ser y fue un poeta plástico y próximo a las cosas, visual y táctil a la vez” (24-5). Me parece pertinente, sin embargo, y para matizar lo apuntado por Ciordia, que el rasgo nominalista que se puede encontrar en ciertos retazos de la escritura nerudiana está atravesada por su impulso utópico de universalidad y totalidad, acaso formando parte del juego dialéctico de las partes y el todo tan caro a su pensamiento poético (Solá 127-8).

${ }^{14} \mathrm{El}$ picoroco es una variedad dentro de los crustáceos sésiles y se cría preferentemente en zonas rocosas. Su parte carnosa se alberga en una concha calcárea de forma tubular. Es un marisco bastante común en las costas del Pacífico chileno.

${ }^{15}$ Para un sucinto análisis del recurso de la aliteración y la consonancia, véase M.H. Abrams (7-8).
} 
Finalmente, los dos últimos versos del poema agudizan la contradicción entre el deseo de representación y el enigma que constituye el picoroco: "pero nadie alcanza el secreto / de su frío castillo gótico." Se vuelve literal, de esta forma, el "pero” del picoroco, su disonancia, su espectro cifrado. En este sentido, esta apariencia pétrea e inanimada no sólo es la condición del ente retratado sino la del poema mismo que leemos, por lo demás atrapado dentro del efecto mediático de la xilografía. Bajo los efectos de la figuración ecfrástica, los entes marinos (referentes), los dibujos y los poemas dependen de una compleja mediación en el plano mismo de la representación.

El penúltimo texto de Maremoto, titulado "Pescadería” y compuesto de ocho versos eneasílabos, precisamente pone en escena un lenguaje poético mediado por el registro plástico. En este poema, el afán nerudiano por aprehender y representar figurativamente sus referentes -específicamente, los peces- deriva en un tipo de orden que evoca, por un lado, la lógica de la exposición y, por otro, el espacio del mercado local:

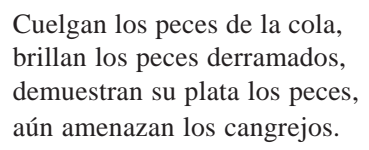

En términos visuales y verbales, estos primeros cuatro versos del poema comportan, al igual que las impresiones xilográficas de Carin Oldfelt, cierto aire familiar con la estética del bodegón. La retórica descriptiva del poema convierte a los peces en modelos expuestos en serie, fijando la imagen de éstos a partir del recurso de la repetición: "los peces". En este sentido, los peces se hallan expuestos en un doble sentido: en un nivel formal, como objetos modelados por los trazos pictórico-verbales del poema y, en un nivel referencial, como mercancías de un espacio de transacción, la pescadería. Sin embargo, el mar vuelve a adoptar un estatus diferente, como lo ilustran los cuatro versos finales de "Pescadería”:

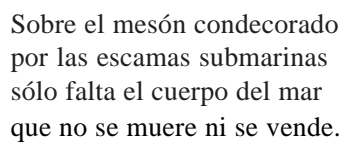

De esta manera, para Neruda, la figura del mar “aparece” como cuerpo que se ausenta, fugándose de la condición transitiva en que se hallan los objetos de mercado, sometidos tanto a la temporalidad de la exhibición (estética) como la transacción (económica). Cabe aquí recordar una vez más el hecho de que, en el orden histórico-social, el mar se mantenía intocado en la plataforma económico-política que los partidos de la Unidad Popular dieran a conocer a inicios de 1970. Se puede decir entonces que la mediación lírica (de Neruda) y el registro económico-político (el discurso de la Unidad Popular), por distintas vías, configuran economías simbólicas que coinciden alrededor de la no-venta del "cuerpo del mar”. 
¿Es posible, entonces, sugerir que, en la poética subyacente a estas páginas, los productos del mar que se exponen a la circulación operan en un nivel análogo al de los poemas, y cuyos sustratos primarios -naturaleza y poesía- constituirían más bien una dimensión sublime? ¿Sería acaso la creación poética una especie de maremoto que arroja los productos de la poesía sobre la superficie del libro? Naturaleza y poesía, como idealidades vacías (en el sentido de Friedrich), terminan así constituyendo un patrimonio intangible, frente al orden perecedero de la cultura letrada, la economía y la sociedad.

Sin embargo, los "productos del mar" quedan inscritos y expuestos sobre la superficie de estas páginas, aunque dentro de espacios acotados de circulación. El carácter artesanal que posee la xilografía dentro del género del grabado y de la plástica, la dimensión local de la pescadería y el tiraje limitado de la primera edición de Maremoto parecen circunscribirlo al ámbito material y simbólico del mercado doméstico. Esta economía local es la que se confirma en el penúltimo poema del libro y cuyo título resulta más que revelador: "Pescadería".

A su vez, los poemas-dibujos exponen los productos del mar dentro del localizado circuito que constituye Maremoto, como una especie de libro-galería, o en términos análogos, como libro-pescadería. En una notable coincidencia del universo nerudiano con la estética kantiana, el orden de lo bello se encarna en estos seres y objetos rescatados del caos oceánico y agrupados para la contemplación y complacencia del yo (autor, sujeto enunciativo, o lector).

De esta manera, los entes marinos quedan incorporados -a manera de souvenirs- a la colección del poeta y, por ende, a su patrimonio. Sin duda que aquí sale a relucir imediatamente la figura histórica y biográfica del autor, cuya obsesión por acumular y coleccionar se hace evidente en su casa de Isla Negra, donde se reúnen caracolas, máscaras, juguetes y antiguedades varias de Chile y el mundo; lo mismo se aprecia en sus casas de Santiago y Valparaíso donde se concentra su patrimonio bibliotecario. ${ }^{16}$ Otra muestra de esta economía simbólica nerudiana se ilustra en la colección de libros y caracolas donados en 1954 por el propio Neruda a la Biblioteca Central de la Universidad de Chile. ${ }^{17}$

Esta “economía patrimonialista”, de acumulación, almacenamiento y colección, puede rastrearse en un trayecto de más larga data y, por cierto, también al interior de los diversos textos de Neruda. Al respecto, recordemos el carácter de “enciclopedia” (Santí 2000,14 ) que comporta el Canto general, o la labor del poeta-arqueólogo que aparece en “Alturas de Macchu Picchu’; o sino la idea de “diccionario” (Concha, “Introducción” 41) o de "inventario de materias elementales, sentimientos, cosas, seres naturales, artefactos"

\footnotetext{
${ }^{16}$ Sobre las casas de Neruda, véase Da Fonseca. Con respecto a la figura del autor, no se puede olvidar el hecho que Pablo Neruda es un seudónimo y que -en su “actuación” literaria- media radicalmente su referente biográfico, Neftalí Reyes Basoalto.

${ }^{17}$ En un acto solemne, en que el rector Juan Gómez Millas recibe la donación, Pablo Neruda dice: "Yo fui recogiendo estos libros de la cultura universal, estas caracolas de todos los océanos y esta espuma de los siete mares la entrego a la Universidad por deber de conciencia y para pagar, en parte mínima, lo que he recibido de mi pueblo” (citado en De Avila Martel, 5). Para mayor información, véase Codocedo Rojas.
} 
(Schopf, 106) que subyace a las Odas elementales; o también el formato del "catálogo" (Marco, 13), en que se inscribe un libro como Arte de pájaros.

Dentro de este contexto, me interesa subrayar la manera en que esta lógica del poetacolector adquiere entidad textual en Maremoto: en primer lugar, como conjunto poético que compila, almacena y cataloga los seres oceánicos mediante el formato del poemadibujo y, en segundo lugar, el hecho que se trate de un volumen de tiraje originalmente reducido.

Al establecerse en Maremoto esta lógica de colección y exposición, se impone también, y a contrapelo de su propia temática, un cierto orden, una organización y una regulación. Congelados por el formato estático y orgánico de los poemas-dibujos, los entes marinos se convierten en figuras hasta cierto punto petrificadas, aunque fantasmagóricamente vivientes. La noción de libro de colección, junto a la secuencia organizadora de los poemas, así como el encuadre que adopta cada uno de ellos, acentúan la tensión entre orden y cataclismo al interior mismo de este corpus poético. A la manera del colector de Benjamin, el poeta de Maremoto experimenta “una tensión dialéctica entre los polos de desorden y orden” (60).

Desde este punto de vista se dramatiza una implícita batalla entre los dominios de la naturaleza y el de la letra, de los objetos poetizados y de la expresión verbal y plástica. El libro de Neruda, en este aspecto, ¿no dramatiza la condición ambigua de los referentes, como espectros del lenguaje, como por ejemplo se dramatiza en los versos finales del poema "Picoroco"? ¿O se trata, más bien, de la tensión de lo animado y lo inaminado, lo dinámico y lo petrificado, lo viviente y lo inánime, que atraviesa el claroscuro de los retratos o los bodegones? ¿ $\mathrm{O}$ se testimonian sino las inestabilidades y costos de un pensamiento dialéctico que, desprendido de la certeza de la síntesis, intenta lidiar con fuerzas contrarias?

En un gesto auto-irónico, el poema nerudiano -en su orden de forma y sentidoparece constituir aquella "torre terrible" que contiene, aunque fracasa en ese acto de contener, el ánima enigmática y el primario acaecer de los seres. Se trata de una encrucijada característicamente moderna de la expresión artística, como bien lo ha definido Theodor Adorno:

Aunque el lenguaje de la naturaleza es mudo, el arte intenta convertir en lenguaje ese silencio, expuesto siempre al fracaso por la inevitable contradicción que hay entre esta idea que exige un esfuerzo desesperado y la otra, a la que se refiere este esfuerzo, de algo absolutamente indeliberado. (107-8)

A lo largo de Maremoto, Neruda melancólicamente hace referencia una y otra vez a la indeterminación arcaica que comporta la naturaleza viviente, ante la cual las concepciones orgánicas de la representación -la del poema, la del dibujo- no tiene otro sino que el del fracaso consignado por Adorno. El carácter ecfrástico del corpus nerudiano-su referencia mediada a los entes marinos- sin duda que patentiza este conflicto. En este aspecto, se confirma también lo que el crítico Saúl Yurkievich definiera, al comentar el poema "El gran océano" de Canto general, como un "transporte hacia la mentalidad primitiva” que, 
en el caso de Neruda, "no puede estar exento de interferencias que corresponden a una conciencia contemporánea y además letrada” (399).

Pero si en el Canto general el sujeto nerudiano contiene dicha contradicción dentro de una “cosmovisión basada en el materialismo dialéctico” (Solá, 128), el Neruda tardío -al menos, el de Maremoto-, parece poner un mayor énfasis en las discontinuidades y fisuras, que en las continuidades y las síntesis de la dialéctica. En efecto, en el último poema del libro, el yo poético se enfrenta, de modo ambivalente, a la mencionada escisión entre naturaleza y letra:

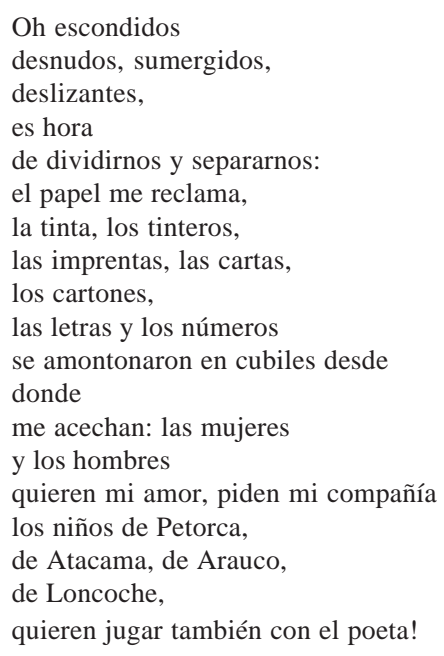

Los primeros versos indican una dramática resignación del poeta ante la condición huidiza y hermética de los entes marinos: “escondidos, desnudos, sumergidos”. Se dramatiza -vía el recurso apostrófico- y se alude a la vez al acto de separación. En dicho umbral, el mar y el poeta se revelan uno al otro, produciéndose una cierta semejanza de atributos entre ambos. Por una parte, ambos constituyen figuras que, de una u otra manera, se hacen presente y se van, como ocurre anticipadamente con "el mar que se fue de viaje" en el poema "Conchas" y ahora, en este texto de clausura, con sus productos y con el propio poeta. Por otra parte, el sujeto poético de estos versos finales termina estableciendo una relación especular con aquél Neptuno humano, festivo y solidario que se nos presenta al inicio del corpus nerudiano: los atributos del maremoto se entremezclan y se funden con aquellos del poeta al interior de la cultura, la política y la sociedad.

En este juego de separación y aproximación con el mundo marino, el poeta finalmente re-sitúa su propio ámbito de acción: el retorno a tierra firme. Las alusiones explícitas a la infraestructura de "la ciudad letrada", para usar el término de Angel Rama, lo reconectan al territorio -en el sentido terrenal y terrestre- de la cultura pública y del espacio nacional: el centro (Petorca), el norte (Atacama) y el sur (Arauco y Loncoche). El viaje a través de 
provincias y pueblos alejados de la capital lo hace parte del vasto paisaje ciudadano de su país. Pero al mismo tiempo que confirma el estatus soberano del mar, como reserva y don, el sujeto opta por retornar juguetonamente a su condición ciudadana y, en última instancia, de poeta. Es posible advertir, en este gesto, un populismo letrado que cobra entidad en el particular uso que Neruda hace del verso corto, es decir, una forma simple, lúdica, festiva y popular. ${ }^{18}$

Este poema final de Maremoto asume así lo nacional-popular tanto en su contenido como en su forma. Tal como aconteciera en sus odas de los 50, el texto mismo adopta en la forma el ancho y largo del territorio chileno. Esto sugiere, si se considera el hecho que este libro se escribe entre 1969 y 1970, una particular manera de registrar un deseo de contacto con la efervescente cultura de masas reinante en ese momento, cuya manifestación más evidente eran las caravanas culturales impulsadas por el conglomerado político de la Unidad Popular en la época y en las que Neruda, ya no como senador o candidato presidencial sino como el poeta, participara activamente..$^{19}$ Este cambio de escena, desde la naturaleza al espacio público nacional, no niega sino que resalta aún más el afán nerudiano por preservar el mar como un trasfondo distante, remoto, casi ausente, en su trascendencia simbólica.

\section{POST-SCRIPTUM}

En 1969, cuando el poeta de Isla Negra comienza a escribir este libro, “se vivía en Chile un clima preelectoral. La conciencia del cambio se había extendido; pero entre las fuerzas que lo querían había una grave dispersión” (Teitelboim 437). El propio Neruda se hallaría en el epicentro de esta efervescencia política, pues el Partido Comunista lo había nominado pre-candidato presidencial ese mismo año. Así, el poeta forma parte de un proceso histórico que contribuiría al surgimiento de la Unidad Popular y al liderazgo de Salvador Allende, cuyo programa democrático-socialista de transformaciones estructurales de la sociedad tomaría cuerpo a partir de la victoria electoral de la izquierda en septiembre de 1970.

Frente a ello, los sectores anti-Unidad Popular, bajo el epíteto de “caos", maniqueamente demonizarán todo este proceso de agitación revolucionaria; discurso que, por lo demás, tendrá continuidad en la retórica del General Pinochet y de los militares tras

\footnotetext{
${ }^{18}$ Este recurso ya tiene antecedentes en las Odas elementales, cuyo "verso exiguo, mínimo a veces," inscrito en "la tradición del verso de arte menor," es, sin duda, uno de sus rasgos más distintivos (Concha, "Introducción” 35-6). Como ya lo he apuntado en una nota previa, "Adiós a los productos del mar” es un poema que, con un predominio del heptasílabo y sin ir más allá del octosílabo, se mueve dentro de dicha tradición, incluyendo formas de versificación tan breves como la del trisílabo o el tetrasílabo.

${ }^{19}$ Este desplazamiento enunciativo confirma lo apuntado por Alain Sicard con respecto a que, en el Neruda de fines de los 60, por un lado, "la especificidad del trabajo poético, por fin reconocida en Las manos del día, opta por expresarse, en lo esencial, aunque tomando cierta distancia” y, por otro, asume su finitud, en tanto la poesía "no es propia esencia y que esta última reside en otra parte, en la materia y en la historia” (Sicard, "El pensamiento poético” 625-626).
} 
el golpe de Estado de 1973. Por lo mismo, desde un punto de vista metafórico, no deja de ser interesante el hecho de que, en el contexto social de fines de los sesenta e inicios del setenta, Neruda intervenga en la escena con un libro que constituye precisamente un elogio a un fenómeno de convulsión y cambio: Maremoto.

Se puede así concluir que esta actitud lúdica y optimista para lidiar con una figura de hecatombe acuática, como lo es el maremoto, se puede leer en conjunción a determinada simpatía nerudiana hacia los procesos políticos y sociales de cambio. Es posible trazar, en este aspecto, con las mediaciones del caso, una cierta conexión entre esta celebración poética del cataclismo y la reivindicación de una perspectiva más general de transformación. En tal sentido, las convulsiones oceánicas dan pie a la contemplación admirativa por parte del poeta y confirman aquel rol ejemplar y pedagógico que ya había encarnado el mar en su Memorial de Isla Negra (1964): “Necesito del mar porque me enseña: no sé si aprendo música o conciencia [...] El hecho es que hasta cuando estoy dormido / de algún modo magnético circulo / en la universidad del oleaje” (87).

En efecto, y tal como lo ha apuntado Jaime Concha, la energía creadora de la naturaleza, así como la continuidad entre lo natural y lo social, son aspectos claves en la obra nerudiana. El crítico sostiene: "lejos de ser claustro de paz, remanso intemporal, la naturaleza poseerá en Neruda un grado notable de eficacia. No es lo idílico lo que predomina de ella: es su energía. No habrá, por tanto, discontinuidad entre la naturaleza y la sociedad en esta poesía” (Concha, Neruda 37). Me parece que este aserto, aunque se basa en el período que abarca desde los primeros libros del poeta hasta los años treinta, resulta igualmente iluminador a la hora de situar un corpus como Maremoto en su clima de época.

En otro nivel, el sujeto lírico de Maremoto, además de situarse a sí mismo dentro de una configuración geográfica de alcance específico, vincula los entes oceánicos a un territorio bastante acotado, como lo hace en el último poema del libro: "Peces, mariscos, algas / escapadas del frío, / volved a la cintura del Pacífico...” El espacio del mar (¿y el de la poesía?), al igual que el lugar público del poeta, aparecen, en este nivel, enmarcados por la geopolítica de la nación. Como ya lo he subrayado en la primera parte del presente ensayo, se trata de un país que, al momento de escribirse este libro, vivía una etapa de enorme convulsión social, política, económica y cultural. Al concluir los sesenta e iniciarse los setenta, Chile experimentaba un clima político caracterizado por un gran protagonismo de las masas, con una izquierda y un movimiento popular empeñados en "profundizar" el modelo de Estado proteccionista y su esquema de "nacionalización” de los recursos naturales (Collier y Sater, 330-358).

La figura del Estado Benefactor, esto es la de un Estado que resguarda y regula el cuerpo social, marcó los discursos políticos, económicos y culturales de la sociedad chilena y, por cierto, el contexto latinoamericano y mundial de gran parte del siglo veinte. Su rol centralizador y planificador se constituyó en la base sustentadora de un modelo de economía cerrada, guiado por la noción dominante de “desarrollo nacional”, junto a una estrategia de industrialización interna. En el caso chileno, este proceso tuvo lugar bajo los liderazgos de los populismos de derecha y los gobiernos radicales y, más tarde, vía el social-cristianismo. Todo ello entre los años treinta y sesenta. El ascenso al gobierno de 
Salvador Allende y la Unidad Popular implicó una “profundización” -para usar un término bastante común en los discursos del período- del referido nacionalismo estatal y económico. La retórica de Estado, y particularmente de la “vía chilena al socialismo,” enfatizaba el resguardo de las riquezas nacionales, dentro de un modelo económico de desarrollo "hacia adentro", ${ }^{20}$

Durante los decenios del cincuenta y del sesenta, el Estado chileno había venido promoviendo un conjunto de leyes internacionales tendientes a salvaguardar la condición del mar como territorio protegido por la nación. Estas iniciativas, que constituyeron respuestas a la pesca indiscriminada puesta en práctica por países como Estados Unidos, dieron origen a significativos pronunciamientos de alcance geopolítico. En agosto de 1952, la "Primera Conferencia sobre Explotación y Conservación de las Riquezas Marítimas del Pacífico Sur”, evento que reuniera a Chile, Ecuador y Perú, reivindicaría "la soberanía y jurisdicción exclusivas que a cada uno de ellos corresponde sobre el mar" que baña sus costas, substituyendo, en el caso chileno, la definición de un mar territorial de 3 millas por uno de 200 (Orrego Vicuña, 11).

Dentro de este marco, el documento programático Con Allende y por la patria: plataforma de gobierno del partido de la Unidad Popular, publicado a inicios del 70, no hizo sino refrendar y continuar dicha política. Más aún, durante este período, el eje del desarrollo económico y social se concentraría en la minería, la metalurgia y la agricultura. Esto significó, al menos en los hechos, mantener el mar en calidad de reserva nacional, limitando su explotación principalmente a la extracción de productos destinados a satisfacer las demandas del mercado de consumo interno.

El libro de Neruda parece coincidir con esta economía política del mar como reserva, aunque, en otro nivel, la amplíe y la desborde por la vía de un elogio poético de mayor alcance simbólico. De alguna manera, la poesía de Neruda constituye una manera de situarse a sí mismo dentro de la coyuntura de fines de la década del 60 e inicios de la siguiente. Y es, precisamente, en 1970 cuando la Sociedad de Arte Contemporáneo, en Santiago de Chile, publica la primera edición de Maremoto, libro que de este modo resulta provocativo de leer tanto en relación con la trayectoria poética de Neruda como con el ímpetu nacionalista y proteccionista predominante en la cultura pública del Chile de la época.

Dicho escenario cambia radicalmente al advenir otro gran remezón de la sociedad chilena: el golpe militar de 1973 y el denominado “ajuste estructural” introducido a la economía nacional a partir de $1975 .{ }^{21}$ La explotación del mar pasa a convertirse en uno de los ejes de un nuevo esquema económico que promovería el cultivo y exportación del salmón a escala global. El auge de la industria salmonera de exportación se constituye en un hito clave en la instalación del emergente modelo de "libre mercado" y en la gestación

\footnotetext{
${ }^{20}$ Para un visión panorámica del amplio período descrito y las políticas económicas y sociales reinantes, consúltense los capítulos "The industrial impulse, 1930s-1960s" (264-302), "Revolution in liberty, 1974-1970" (305-29) y “The Chilean road to socialism, 1970-73” (330-358) del libro A History of Chile 1808-1994 de Simón Collier y William Sater.

${ }^{21}$ Para un recuento y análisis de esta etapa, véase el capítulo titulado “The Pinochet years” en Collier y Sater (359-389).
} 
de una nueva generación empresarial en el Chile de la época. El cultivo del salmón era una línea de inversión y producción inexistente hasta inicios de los 70, lo mismo que la explotación de las aguas del Pacífico chileno que pasan a tener rol esencial en este nuevo y masivo ámbito de producción y comercialización de carácter trasnacional (Montero, 249-251). El nuevo modelo exportador chileno comenzaba así a tocar “el cuerpo del mar,” ya no tanto para incorporarlo al “mesón” del mercado doméstico -la pescadería-sino a las transacciones de un mercado global. ${ }^{22}$

Esta nueva escena implica un revés dramático para la imaginación económica y cultural del territorio soberano, en particular, para una economía del patrimonio. La figura trascendente y eterna del “cuerpo del mar” queda sujeta a las contingencias de la inversión y acumulación de los nuevos capitales. El propio deceso del poeta en 1973 cohabita, en este sentido, con una muerte de alcance más global: el fin de una determinada relación entre Estado, nación y naturaleza, así como la crisis de una economía de signo nacional y proteccionista. Tras la muerte de Neruda y el advenimiento del ajuste, ¿cómo situar entonces una metaforización trascendente del “cuerpo del mar” cuando éste ya no es sino cuerpo subsumido en las redes del capital global? ¿Cómo repensar el lugar del poeta en circunstancias que se han trastocado sus referentes simbólicos?

En este nuevo escenario, resulta interesante que el prólogo de la segunda edición de Maremoto haya estado a cargo del poeta Raúl Zurita, quien, especialmente hacia fines de los 80 y en el contexto de la transición a la democracia en Chile, ha buscado retomar la función pública del poeta y su posición próxima al Estado, además de vincular su escritura a la geografía de la nación. En el "Prólogo" de Zurita hay, sin duda, un gesto de recuperación emblemática de Neruda, la poesía y la naturaleza. A su juicio, en los versos de Maremoto habría un llamado para “que lo muerto resucite, que retorne la vida.” Desde 1991, cuando Chile vivía la promesa de la recién retornada democracia, hasta hoy día, el modelo de la economía abierta y transnacionalizadora se ha intensificado en el país y ha quedado atrás el viejo modelo del Estado benefactor y sus políticas proteccionistas.

De este modo, el 2004, año del centenario de Neruda, ha acontecido también en un escenario en que el locus del mar y la naturaleza, del poeta y la poesía, y el de la propia cultura nacional, aparecen radicalmente reconfigurados. Sin duda que, frente a esta encrucijada, navegar la lírica oceánica de Neruda implica en la actualidad una experiencia históricamente situada, abierta a más tenues y menos monumentales recuperaciones de lo simbólico, en las condiciones de una naturaleza y una cultura que se resemantizan dentro del impetuoso y pujante oleaje de un mercado transnacionalizado.

\footnotetext{
${ }^{22}$ Esto se reflejará en dos tendencias expresivas del impacto del modelo de economía abierta sobre la circulación económica de los productos del mar. Por un lado, tras el "boom” de la salmonicultura y la industria pesquera de exportación desde su emergencia a fines de los 70, en 1986 se crea una Asociación de Productores de Salmón y Trucha, agrupando a 42 empresas chilenas, entre cuyos objetivos estaba el de “promover el salmón chileno en el extranjero.” En este cuadro, en 1993, Chile se convertirá en el segundo productor de salmón, detrás de Noruega, en el mercado mundial. Por otra parte, Salmones Antártica, empresa que surge como parte del proyecto pionero de cultivo artificial del salmón en Chile, en 1988, se vende en US\$21 millones a la compañía japonesa Nipon Suisan (Montero, 251).
} 
Abrams, M.H. A Glossary of Literary Terms. Fort Worth/Dallas: Hartcourt Brace College, 1993.

Adorno, Theodor. Teoría estética. Fernando Riaza, trad. Buenos Aires: Ediciones Orbis, 1983.

Alonso, Amado. Poesía y estilo de Pablo Neruda. Buenos Aires: Editorial Sudamericana, 1968.

Bachelard, Gaston. L'eau et les rêves. Essai sur l'imagination de la matière. Paris: Librairie José Corti, 1942.

Benjamin, Walter. “Unpacking My Library: A Talk about Book Collecting”. Illuminations. Harry Zohn, trad. New York: Schocken Books, 1985. 59-67.

Ciordia, Javier. "Neruda: teoría y praxis poética”. Nuevas aproximaciones a Pablo Neruda. Angel Flores, ed. México: Fondo de Cultura Económica, 1987. 13-25.

Codoceo Rojas, María. Catálogo de las conchas de la colección Pablo Neruda en la Biblioteca Central de la Universidad de Chile. Santiago: Editorial Universitaria, 1987.

Collier, Simon y William F. Sater. A History of Chile 1808-1994. Cambridge: Cambridge University Press, 1990.

Concha, Jaime. “Introducción”. Odas elementales de Pablo Neruda. Madrid: Ediciones Cátedra, 1999. 15-54. Neruda. Santiago: Editorial Universitaria, 1972.

De Avila Martel, Alamiro. "Prólogo". Catálogo de las conchas de la colección Pablo Neruda en la Biblioteca Central de la Universidad de Chile de María Codoceo Rojas. Santiago: Editorial Universitaria, 1987. 5-7.

Da Fonseca, María Cristina. Y una última pregunta: ¿cómo viven los poetas? (las casas de Pablo Neruda. Santiago: Editorial Cuarto Propio, 2000.

Franco, Jean. "Orfeo en utopía: el poeta y la colectividad en Canto general”. Simposio Pablo Neruda Actas. Columbia: University of South Carolina Las Américas, 1974. 267-289.

Friedrich, Hugo. The Structure of Modern Poetry. Joachim Neugroschel, trad. Evanston: Northwestern University Press, 1974.

Kant, Immanuel. Crítica del juicio. José Rovira Armengol, trad. Buenos Aires: Editorial Losada, 1993.

Krieger, Murray. The Ekphrastic Principle and the Still Movement of Poetry. Durham: Duke University Press, 2003.

López Bueno, Begoña. Lira templada. Estudios sobre poesía del siglo de oro. Granada: Editorial Don Quijote, 1990.

Loyola, Hernán. “Notas”. Maremoto / Aún / La espada encendida / Las piedras del cielo. Barcelona: De bolsillo, Random House Mondadori, 2004. 163-173.

Marchese, Angelo y Joaquín Forradellas. Diccionario de retórica, crítica y terminología literaria. Barcelona: Editorial Ariel, 2000. 
Marco, Joaquín. "Prólogo: poeta de senectud, poeta de renovación”. Pablo Neruda Obras completas III: De “Arte de pájaros” a "El mar y las campanas” 1966-1973. Hernán Loyola, ed. Barcelona: Galaxia Gutenberg, 2000. 9-48.

Meller, Patricio. Los Chicago Boys y el modelo económico chileno: 1973-1983. Santiago: Apuntes CIEPLAN, 1984.

Méndez-Ramírez, Hugo. Neruda’s Ekphrastic Experience: Mural Art and Canto General. Londres: Bucknell University Press, 1999.

Montero, Cecilia. La Revolución Empresarial Chilena. Santiago: Dolmen Ediciones, 1997.

Neruda, Pablo. Canto general. [1950] Madrid: Ediciones Cátedra, 2000. Maremoto. Santiago: Pehuén Editores, 1991.

Maremoto. Santiago: Sociedad de Arte Contemporáneo, 1970.

Fin de mundo. Buenos Aires: Editorial Losada, 1969.

La barcarola. [1967]. Barcelona: De bolsillo, 2004.

Arte de pájaros. Santiago: Ediciones Sociedad de Amigos del Arte Contemporáneo, 1966.

Memorial de Isla Negra. III: El fuego cruel. Buenos Aires: Editorial Losada, 1964. Odas elementales. Buenos Aires: Editorial Losada, 1954.

Residencia en la tierra. Madrid: Ediciones del árbol, 1935.

Ortega, Julio. El discurso de la abundancia. Caracas: Monte Avila Editores, 1990.

Orrego Vicuña, Francisco. Chile y el derecho del mar. Santiago: Editorial Andrés Bello, 1972.

Rimbaud, Arthur. Le bateau ivre et autres poèmes. Paris: Livrio, 2003.

Santí, Enrico Mario. “Introducción”. Canto general. Madrid: Ediciones Cátedra, 2000. 794.

S/A. Con Allende y por la patria: plataforma de gobierno del partido de la Unidad Popular.

Schopf, Federico. Del vanguardismo a la antipoesía: ensayos sobre la poesía en Chile. Santiago: LOM Ediciones, 2000.

Sicard, Alain. "Lo breve y lo interminable: a propósito del Libro de las preguntas de Pablo Neruda”. Nerudiana (1995): 146-153.

El pensamiento poético de Pablo Neruda. Madrid: Editorial Gredos, 1981.

Solá, María Magadalena. Poesía y política en Pablo Neruda (análisis del "Canto general”). Río Piedras: Editorial Universitaria, 1980.

Spitzer, Leo. La enumeración caótica en la poesía moderna. Raimundo Lida, trad. Buenos Aires: Facultad de Filosofía y Letras de la Universidad de Buenos Aires, Instituto de Filología, 1945.

Teitelboim, Volodia. Neruda. México: Editorial Hermes, 1996.

Yurkievich, Saúl. Fundadores de la nueva poesía latinoamericana. Barcelona: Edhasa, 2002.

"El génesis océanico”. Simposio Pablo Neruda Actas. Columbia: University of South Carolina Las Américas, 1974. 384-399. 
